\title{
Pengaruh Religiusitas Terhadap Pemilihan Pakaian pada Wanita Muslim
}

\author{
Ivon Sandya Sari Putri \\ Jurusan Administrasi Niaga, Politeknik Negeri Bandung, Indonesia
}

\begin{abstract}
:
This research provides information about religiosity matter toward Muslim women's behavior in clothing selection. From 339 data respondents using regression analysis, it showed that religiosity has a negative effect on clothing brand attributes and Muslim women consider the comfort of clothing elements more. From the result of this study, it looks like a great opportunity for potential entrepreneurs who don't have a popular brand yet to enter the Muslim women's clothing industry.
\end{abstract}

Keywords: Clothing choice, Religiosity, Women Muslim Behavior

\begin{abstract}
Abstrak:
Penelitian ini memberikan informasi mengenai perilaku wanita Muslim terhadap pemilihan pakaian ketika berbelanja dilihat dari segi religiusitas. Dari data yang diolah sebanyak 339 responden menggunakan analisis regresi menunjukkan bahwa religiusitas berpengaruh negatif terhadap atribut merk pakaian dan para wanita Muslim lebih mempertimbangkan unsur kenyamanan pakaian. Dari hasil penelitian ini, terlihat kesempatan yang besar bagi para calon pelaku usaha yang belum mempunyai merek populer untuk bisa masuk dalam industri pakaian wanita Muslim.
\end{abstract}

Kata kunci: Atribut Pemilihan Pakaian, Perilaku Wanita Muslim, Religiusitas

\section{Pendahuluan}

Menurut laporan Thomson Reuteurs \& Dinar Standard diambil dari The State of The Global Islamic Economy 2015-2016, konsumen Muslim menghabiskan sekitar US\$230 miliar untuk pakaian, dan diproyeksikan akan mencapai US\$ 327 miliar pada 2019. Perkembangan industri pakaian di seluruh dunia dimainkan oleh berbagai perusahaan pakaian mulai dari perusahaan lokal kecil sampai perusahaan pakaian merek terkenal. Yang cukup menarik dalam industri pakaian terutama di Indonesia, terdapat banyak wanita Muslim yang aktif sebagai desainer, produsen, sekaligus konsumen pada industri ini. Beberapa wanita Muslim yang terjun dalam industri ini dimulai dengan melakukan kegiatan dakwah Islam, dan kemudian menjadi selebritas wanita Muslim, dan mulai membangun bisnis di bidang ini. Banyak dari mereka yang menjadi pusat trend fashion pakaian Islami dengan gaya berpakaian yang berbeda-beda.

Gaya pakaian wanita Muslim sangat heterogen, terutama di Indonesia dimana populasi Muslim terbesar ada. Dimulai dari gaya berpakaian tradisional wanita Muslim yang dapat terlihat dari penggunaan gamis panjang yang sederhana dengan aneka warna serta mengenakan jilbab hitam panjang yang longgar yang biasanya dikaitkan dengan gaya Arab dengan atau tanpa penutup wajah (cadar). Gaya selanjutnya disebut jilbab modern dengan kombinasi jilbab, jeans dan tunik yang telah dipengaruhi oleh budaya Barat (Jones, 2007).

Penggunaan pakaian tersebut merupakan perintah dari Allah SWT bagi wanita Muslim untuk memakai kain yang menutupi seluruh tubuh kecuali wajah dan telapak tangan, seperti yang tertulis pada Al Qur'an, "Wahai Nabi! Katakanlah kepada isteri-isterimu, anak-anak perempuanmu dan isteri-isteri 
orang mu'min: Hendaklah mereka mengulurkan jilbabnya ke seluruh tubuh mereka". Yang demikian itu supaya mereka lebih mudah untuk dikenal, karena itu mereka tidak diganggu. [...]. (Al-Qur'an 33: 59). Islam mengijinkan pakaian apapun yang memenuhi kesopanan yang diperlukan untuk wanita yang layak, dan kreativitas perancang mode harus menggabungkan keanggunan dan kesopanan dalam gaun wanita karena seseorang tidak meniadakan yang lain (Osman, 2016).

Doward (2016) dari Guardian.com mengutip Khattab dan Modood yang mengatakan 25\% wanita Muslim berusia 21-24 sekarang memiliki pendidikan tinggi, dibandingkan dengan 22\% pria Muslim pada usia yang sama. Berdasarkan Badan Pusat Statistik Indonesia, 77\% populasi wanita Muslim di Indonesia berada di usia muda antara 0-40 tahun pada tahun 2010. Menurut Blackburn (2016) yang mengutip dari Arif Zamhari, Bianca Smith dan Julian Millie, mengatakan bahwa perempuan menunjukkan tingkat komitmen yang mencolok dalam pencarian mereka untuk pengetahuan agama melalui pertemuan doa rutin dan pertemuan agama lainnya. Wanita muslim saat ini sangat muda, aktif dan terdidik. Pemilihan pakaian merupakan salah satu hal penting untuk mendukung aktivitas mereka. Namun, bagaimana sebenarnya para wanita Muslim memilih pakaian mereka?

Dalam penelitian ini kami ingin menguji apakah ketika kode busana pakaian wanita Muslim diperintah oleh Qur'an dan Sunnah, yang terkait dengan aspek agama, apakah hal agama mempengaruhi sikap mereka terhadap atribut pakaian. Menurut Gokariksel \& Sekor (2009), studi yang mengaitkan aspek religiusitas dan fashion telah mulai mendapatkan perhatian yang menjelaskan bagaimana Muslim bisa menjadi modis, sederhana dan cantik dengan penampilannya. Menurut Delener (1990), agama adalah bagian penting dari budaya yang dapat mempengaruhi perilaku orang dan keputusan pembelian. Sejalan dengan Wilkes et al. (1986) dalam penelitian mereka yang menunjukkan pengaruh religiusitas pada beberapa gaya hidup konsumen, yang mungkin memengaruhi perilaku pilihan orang. Selain itu, beberapa penelitian menunjukkan bahwa religiusitas mempengaruhi risiko yang dirasakan dalam keputusan pembelian barang tahan lama (Delener, 1990), perilaku belanja pakaian olahraga (Taks \& Shreim, 2009), dan orientasi belanja (Mokhlis, 2006). Juga, Essoo \& Dibb (2004) menunjukkan bahwa tingkat religiusitas konsumen bervariasi dalam perilaku belanja mereka khususnya. Penelitian ini memberikan kontribusi untuk menambahkan sudut pandang di daerah penelitian ini dengan fokus pada pengaruh religiusitas terhadap pemilihan pakaian.

\section{Kajian Literatur \\ Religiusitas}

Sebagai bagian dari budaya, nilai agama dalam individu dan masyarakat merupakan aspek penting yang mempengaruhi sikap, nilai, dan perilaku individu (Mokhlis, 2009). Essoo \& Dibb (2004) menyebutkan bahwa "religiositas adalah derajat di mana keyakinan dalam nilai-nilai agama tertentu dan cita-cita dipegang dan dipraktekkan oleh seorang individu." Menurut Allport (1950), religiusitas dapat dibagi menjadi intrapersonal (intrinsik) religiusitas dan interpersonal religiusitas (ekstrinsik). Dia mencatat bahwa "religiusitas intrapersonal didefinisikan sebagai agama sebagai kerangka kerja yang memberi makna tentang yang dipahami semua kehidupan", sedangkan, dalam Donahue (1985), religiusitas antarpribadi didefinisikan sebagai "agama kenyamanan dan konvensi sosial, sebuah pelayanan diri, pendekatan instrumental yang dibentuk untuk melayani diri sendiri." Donahue (1985) juga mencatat bahwa" konstruk ekstrinsik tidak mengukur agama per se, tetapi mengukur sikap seseorang terhadap agama sebagai sumber kenyamanan dan dukungan sosial." Individu yang memiliki keyakinan yang tinggi terhadap agama atau keterlibatan tinggi dalam kelompok agama cenderung memanfaatkan agama mereka sebagai prinsip pengorganisasian dalam pengambilan keputusan individu (Mokhlis, 2006). Orang-orang yang terlibat dalam kegiatan keagamaan memiliki efek pada tanggapan mereka sehubungan dengan perilaku mereka di pasar daripada keyakinan mereka dalam doktrin agama (Muhamad \& Mizerski, 2010).

\section{Atribut Pakaian}

Pakaian dilihat sebagai sesuatu hal yang melayani kebutuhan individu, sosial, dan fisik manusia, serta menawarkan representasi budaya dan bentuk seni (Kaiser, 1997). Jadi pakaian kita mengekspresikan identitas kita, memberi tahu orang lain sesuatu tentang jenis kelamin, kelas, status, atau sikap konsumen kita (Kaiser, Chandler, \& Hammidi, 2001). Di India, sebagian besar wanita berfokus pada karakteristik 
produk, trend, dan faktor lain yang terkait dengan kebutuhan sosial atau psikologis (Singh \& Sarvanan, 2013). Beberapa atribut pakaian juga penting yaitu harga, warna, kualitas produk, merek, kenyamanan, \& fashionabilitas (Taylor \& Cosenza, 2002; Birtwistle \& Tsim, 2005).

Ketika orang mempertimbangkan untuk membeli barang, mereka akan membandingkan semua opsi atau fitur alternatif produk. Beberapa aspek seperti estetika (Eckman et al, 1990), harga dan kualitas (Lang \& Crown, 1993) adalah pertimbangan penting ketika membuat keputusan untuk memilih pakaian. Menurut Eckman et al. (1990), harga dan merek adalah atribut yang paling sering digunakan oleh konsumen dalam menilai pakaian. Beaudoin et al. (2000) menemukan 12 atribut yang berhubungan dengan sikap ketika membeli pakaian seperti kecocokan, daya tahan, kemudahan perawatan, harga yang menguntungkan, kenyamanan, kualitas, warna, daya tarik, fashionable, nama merek, kesesuaian untuk acara, dan pilihan gaya. Menurut Fairchild Dictionary of Fashion, fashion adalah kebiasaan atau gaya berpakaian yang berlaku di antara setiap kelompok orang. Orang memilih kain dan warna untuk membantu mereka menyesuaikan diri dengan citra diri ideal mereka (Rosenfeld \& Plax, 1977). Estetika pakaian adalah tentang bagaimana orang memilih untuk tampil, dan cara mereka ingin melihat diri mereka sendiri dan orang lain dalam konteks tertentu (DeLong, 2016).

\section{Metode Penelitian}

Populasi dan Sampel

Populasi dari penelitian adalah wanita yang menganut agama Islam di Indonesia. Sedangkan sample dari penelitian ini adalah menggunakan teknik sampling acak dimana seluruh wanita Muslim di Indonesia dapat menjadi sample dalam penelitian ini.

\section{Instrumen Penelitian}

Instrumen penelitian yang digunakan untuk penelitian ini berupa kuesioner yang terdiri atas tiga bagian. Bagian pertama adalah data yang diperlukan untuk mengetahui informasi profil responden yaitu usia, tingkat pendidikan, dan pekerjaan. Bagian kedua merupakan pertanyaan yang diadopsi dari Religious Commitment Inventory yang terdiri dari 10 pernyataan dengan pilihan skala Likert 1-5. Kemudian di bagian ketiga terdapat 20 pernyataan untuk mengukur penilaian responden terhadar atribut pemilihan pakaian. Penilaian kuesioner ini diukur menggunakan skala Likert 1 sampai 5 yang disesuaikan dengan jenis pernyataan sehingga memungkinkan responden untuk memilih jawaban sesuai dengan apa yang mereka rasakan. Analisis deskriptif dan analisis regresi digunakan untuk melihat bagaimana pengaruh antar kedua variabel.

\section{Hasil dan Pembahasan \\ Hasil Analisis Data}

Dari data yang diambil sebanyak 339 responden, diperoleh profil responden seperti yang tertera pada Tabel 1. Dilihat dari sebaran responden, responden terbanyak berada pada usia 21-25 tahun. Responden didominasi oleh wanita Muslim dengan tingkat pendidikan sarjana dan juga pelajar/ mahasiswa.

Tabel 1 Profil Responden

\begin{tabular}{lll}
\hline Profil Responden & & Frekuensi \\
\hline \multirow{4}{*}{ Usia } & $<20$ tahun & 53 \\
& $21-25$ tahun & 192 \\
& $26-30$ tahun & 53 \\
& $31-35$ tahun & 13 \\
& $36-40$ tahun & 5 \\
& $41-45$ tahun & 5 \\
Tingkat & $>45$ tahun & 4 \\
Pendidikan & SMA & 29 \\
& Diploma & 56 \\
& Sarjana & 163 \\
& Master & 72 \\
\hline
\end{tabular}




\begin{tabular}{lll}
\hline & Pelajar & 169 \\
& Pegawai Swasta & 81 \\
Pekerjaan & PNS & 24 \\
& Wiraswasta & 13 \\
& Ibu Rumah Tangga & 16 \\
& Guru/ Dosen & 9 \\
& Lain-lain & 13 \\
\hline
\end{tabular}

Dari data yang telah didapatkan, terlihat bahwa secara umum, tingkat religiusitas seluruh responden wanita Muslim cukup tinggi $(M=3.6)$. Sedangkan bila dilihat dari tingkat intrapersonal religiusitas dan interpersonal religiusitas, data menunjukkan bahwa wanita Muslim di Indonesia memiliki tingkat intrapersonal religiusitas yang lebih tinggi $(\mathrm{M}=4.19)$ dibandingkan dengan interpersonal religiusitas $(\mathrm{M}=3.48)$.

Berdasarkan hasil analisis deskriptif untuk atribut pakaian yang mempengaruhi pemilihan pakaian wanita Muslim, terdapat lima indikator yaitu aestetik, fashionabilitas, merk, harga, dan kenyamanan. Diantara lima indikator tersebut, atribut yang paling menjadi pertimbangan bagi responden adalah berkaitan tentang kenyamanan pakaian $(\mathrm{M}=3.87)$, kemudian aestetik $(\mathrm{M}=3.77)$ dan atribut yang mempunyai tingkat pertimbangan paling kecil adalah merk $(\mathrm{M}=2.31)$ juga fashionibilitas $(\mathrm{M}=2.35)$.

Berdasarkan hasil analisis regresi sederhana untuk pengaruh intrapersonal dan interpersonal religiusitas terhadap masing-masing atribut pakaian, dapat dilihat pada Tabel 5, menunjukkan bahwa fashionability dipengaruhi secara negative oleh intrapersonal religiusitas $(\beta=-.312$, sig $=.000)$ dan interpersonal religiusitas $(\beta=-.148$, sig <.05).

\section{Pembahasan}

Penelitian ini mengukur bagaimana tingkat religiusitas pada wanita Muslim yang terdiri dari intrapersonal religiusitas dan interpersonal religiusitas. Religiusitas tersebut kemudian dihubungkan dengan perilaku pemilihan pakaian pada wanita Muslim, apakah tingkat religiusitas berpengaruh pada wanita Muslim dalam cara mereka memilih pakaian.

Berdasarkan hasil analisis data regresi, terlihat bahwa religiusitas berhubungan negative dengan aestetik, fashion, merk, dan harga. Sedangkan mempunyai hubungan yang positif dengan aspek kenyamanan dalam pemilihan pakaian wanita Muslim. Hal yang sangat terlihat signifikan adalah hubungan antara religiusitas dengan aspek fesyen dimana religiusitas berpengaruh secara negative terhadap fashion sebagai salah satu atribut pakaian.

Dilihat dari hasil analisis, tingkat religiusitas responden lebih lebih tinggi pada intrapersonal religiusitas dibandingkan interpersonal religiusitas. Para responden yakin bahwa agama yang dianutnya mempengaruhi seluruh urusan dalam hidup mereka. Akan tetapi para responden tidak banyak memberikan kontribusi terhadap organisasi keagamaan.

Komitmen religiusitas intrapersonal dan interpersonal, keduanya merupakan faktor yang dapat menentukan sikap wanita Muslim terhadap fashion secara negatif. Oleh karena itu, umat Islam dengan tingkat religiusitas yang tinggi akan mengikuti aturan kewajiban agama lebih ketat yang berarti mereka tidak tertarik pada mode yang berfungsi untuk mengekspos identitas mereka, status, dll, kepada orang lain. Sikap negatif terhadap mode juga berarti mereka tidak selalu mengikuti mode baru setiap waktu, dan mengikuti apa yang digunakan oleh teman atau selebriti mereka pada pakaian mereka. Kenyamanan dalam berpakaian merupakan atribut yang paling menjadi pertimbangan oleh wanita Muslim dalam memilih pakaian.

\section{Kesimpulan}

Berdasarkan dari hasil analisis dan pembahasan yang telah diuraikan pada bagian sebelumnya, maka dapat ditarik kesimpulan bahwa religiusitas yang terdiri dari intrapersonal dan interpersonal religiusitas secara signifikan mempengaruhi perilaku konsumen wanita Muslim dalam pemilihan pakaian terutama berkenaan dengan merk.

Hal tersebut mengidentifikasikan bahwa konsumen wanita Muslim dengan tingkat religiustas tertentu tidak memikirkan merk atau merk tidak menjadi sebuah bahan pertimbangan dalam memilih sebuah pakaian. Hal ini sangat bermanfaat bagi bisnis pakaian kecil dan local yang ingin menyasar 
konsumen wanita Muslim untuk pertama kali. Banyak peluang yang dapat dikembangkan dalam industry pakaian wanita Muslim khususnya di Indonesia.

Dari hasil penelitian ini, terlihat bahwa wanita Muslim memilih pakaian mereka dengan unsur kenyamanan yang paling utama. Oleh karena itu, para pelaku industry pakaian wanita Muslim, dapat meningkatkan unsur kualitas kenyamanan pada produk mereka dengan menggunakan bahan yang berkualitas dan nyaman dipakai. Ditambah dengan tingkat aestetik yang juga menjadi pertimbangan konsumen wanita Muslim, pelaku industry juga dapat meningkatkan nilai estetika pada pakaian yang diproduksi terutama berkaitan dengan warna pakaian.

\section{Daftar Pustaka}

Alam, S., Mohd, R., \& Hisham, B. (2011). Is religiosity an important determinant on Muslim consumer behaviour in Malaysia? Journal of Islamic Marketing, 2 (1), 83-96.

Al-Hashimi, M. A. (2008, June). The Ideal Muslimah: The True Islamic Personality of the Muslim Woman as Defined in the Qur'an and Sunnah. Retrieved from thequranblog.files.wordpress.com

Allport, G. (1950). The individual and his religion: A psychological interpretation. New York: MacMillan.

Bachleda, C., Hamelin, N., \& Benachour, O. (2014). Does religiosity impact Moroccan Muslim women's clothing choice. Journal of Islamic Marketing,. 5 (2), 210-226.

Beaudoin, P., Moore, M. A., \& Goldsmith, R. E. (2000). Fashion Leaders' and Followers' Attitudes Toward Buying Domestic and Imported Apparel. Clothing \& Textiles Research Journal, 18 (1), 5664.

Birtwistle, G., \& Tsim, C. (2005). Consumer purchasing behaviour: An investigation of the UK mature women's clothing market. Journal of Consumer Behaviour, 6 (4), 453-464.

Blackburn, S. (2016, July 12). Women and Islam. Retrieved from Inside Indonesia: http://www.insideindonesia.org

Brenner, S. (1996). Reconstructing self and society: Javanese Muslim women and "the veil". American Ethnologist, 23 (4), 673-697.

Burroughs, J., \& Rindfleisch, A. (2002). Materialism and well-being: a conflicting values perspective. Journal of Consumer Research, 29 (3), 348-370.

Chernev, A. (2004). Goal--Attribute Compatibility in Consumer Choice. Journal of Consumer Psychology, 141-150.

Delener, N. (1990). The effects of religious factors on perceived risk in durable goods purchase decision. Journal of Consumer Marketing, 7 (3), 27-38.

Delener, N. (1994). Religious contrasts in consumer decision behaviour patterns: their dimensions and marketing implications. European Journal of Marketing, 28 (5), 36-53.

DeLong, M. (2016). Aesthetic of Dress. Retrieved from Berg Fashion Library: www.bergfashionlibrary.com

Diwan, J. (2014, November 3). The Complete Islamic Personality: Personal development according to Islamic teachings. Retrieved from Why Islam: http://www.whyislam.org

Donahue, M. (1985). Intrinsic and extrinsic religiousness: Review and meta analysis. Journal of Personality and Social Psychology, 48 (2), 400-419.

Dost, H. V., \& Sabet, Z. M. (2016). An Empirical Survey on Islam Religion Role and Customer Status Consumption Consistency in Fashion Clothing Brands. Retrieved from www.dehkadeyemaghaleh.ir

Doward, J. (2016, Aprl 2). Young Muslim women take lead over men in race for degrees. Retrieved from The Guardian: https://www.theguardian.com

Essoo, N., \& Dibb, S. (2004). Religious influences on shopping behaviour: an exploratory study. Journal of Marketing Management, 20, 683-712.

Farrag, D., \& Hassan, M. (2015). The influence of religiosity on Egyptian Muslim youth's attitude towards fashion. Journal of Islamic Marketing, 6 (1), 95-108.

Gokariksel, B., \& Secor, A. (2009). New Transtional Geographies of Islamic and Capitalism and Subjectivity: The veiling-fashion industry in Turkey. Area, 41(1), 6-18.

Gokariksel, B., \& Secor, A. (2010). Between Fashion and Tesettur: Marketing and Consuming Women's Islamic Dress. Journal of Middle East Women's Studies, 6 (3). 
Hamdan, A. (2006). Arab women's education and gender perceptions: An insider analysis. Journal of Internation Women's Studies, 8(1). Retrieved from www.bridgew.edu/soas/jiws

Kaiser, S. (1997). The Social Psychology of Clothing: Symbolic Appearances in Context (2nd Revised ed.). New York: Fairchild.

Lang, J. Q., \& Crown, E. (1993). Country-of-origin effect in apparel choices: A conjoint analysis. International Journal of Consumer Studies, 17 (1), 87-98.

Mokhlis, S. (2006). The effect of religiosity on shopping orientation: an exploratory study in Malaysia. Journal of American Academy of Business, 9 (1), 64-74.

Mokhlis, S. (2008). Consumer Religiosity and The Importance of Store Attributes. The Journal of Human Resource and Adult Learning, 4 (2), 122-133.

Mokhlis, S. (2009). Relevancy and Measurement of Religiosity in Consumer Behaviour Research. International Business Research, 2 (2).

Muhamad, N., \& Mizerski, D. (2010). Exploring Muslim Consumes' Information Sources for Fatwa Rulings on Products and Behaviours. Journal of Islamic Marketing, 1(2), 124-135.

Mulali, A. (2009). Hijab fashion and Islamic clothing: Hot and trendy. Retrieved from www.ideamarketers.com

O'Cass, A., \& Frost, H. (2002). Status brands: examining the effects of non-product-related brand associations on status and conspicuous consumption. The Journal of Product \& Brand Management, 11 (2), 67-86.

O'Cass, A., Lee, W. J., \& Siahtiri, V. (2013). Can Islam and status consumption live together in the house of fashion clothing? Journal of Fashion Marketing and Management: An International Journal, 17(4), 440-459.

Omair, K. (2009). Arab women managers and identity formation through clothing. Gender in Management: An International Journal, 24 (6), 412-431.

Osman, M. (n.d.). Muslim Women: The Family and The Society. Retrieved from http://www.usc.edu

Penduduk Menurut Kelompok Umur dan Agama yang Dianut-Sensus Penduduk 2010. (n.d.). Retrieved from Badan Pusat Statistik: http://sp2010.bps.go.id/index.php/site/tabel?tid=320\&wid=0

Rosenfeld, L. B., \& Plax, T. G. (1977). Clothing as Communication. Journal of Communication. 27 (2), 24-31.

Shreim, M. (2009). Religion and Sports Apparel Consumption: An Exploratory Study of the Muslim Market. Electronic Theses and Dissertations.

Shukor, S. A. (2011). Factors Influence British Muslim Clothing Choice in the United Kingdom (UK). European Advances in Consumer Research, 9, 572-573.

Singh, N., \& Sarvanan, R. (2013). A Comprehensive Study on Female Buying Behaviour for Apparel Segment in Coimbatore. International Journal of Textile and Fashion Technology, 3 (1), 67-82.

Spilka, B., Hood, R., Hunsberger, B., \& Gorsuch, R. (2003). The psychology of religion, 3rd edition. New York: Guilford.

(2016). State of The Global Islamic Economy Report 2015/16. Thomson Reuters \& Dinar Standard.

Taylor, S., \& Cosenza, R. (2002). Profiling later aged female teens: mall shopping behavior and clothing choice. The Journal of Consumer Marketing, 393.

Turner-Bowker, D. (2001). How can you pull yourself up by your bootstraps, if you don't have boots? Work-appropriate clothing for poor women. Journal of Social Issues, 57 (2), 311-322.

Wilkes, R., Burnett, J., \& Howell, R. (1986). On the Meaning and Measurement of Religiosity in Consumer Research. Journal of the Academy of Marketing Science, 14, 47-56.

Worthington, E., Wade, N., Hight, T., McCullough, M., Berry, J., Ripley, J., . . Bursley, K. (2003). The religious commitment inventory-10: development, refinement and validation of a brief scale for research and counseling. Journal of Counseling Psychology, 50 (1), 84-96.

*Email korespondensi:

ivon.sandya@polban.ac.id 